\title{
Coagulation and fibrinolysis after injury
}

\author{
P. T. FLUTE \\ From King's College Hospital Medical School, London
}

The direct and indirect effects of injury are to stimulate coagulation and fibrinolysis, almost immediately, in direct proportion to the severity of the trauma, and with effects which are both local and remote from the site of damage. A series of blood changes follows in quick succession and may lead to a phase of apparent hypocoagulability and reduced fibrinolysis, although even at this stage there is evidence of continued stimulation of both systems. It is important to examine the mechanism of these changes in order to understand, and to be prepared to counter, the sudden haemostatic failure or thromboembolism which may result.

The accelerated blood clotting after injury is easy to see. William Hewson, describing the killing of sheep in 1772, observed that 'the blood which issued last coagulated first'. Stimulation of fibrinolysis is less readily appreciated but the unusually fluid character of the blood at necropsy in cases of violent death was commented on by Morgagni (1769) and by John Hunter (1794). The frequent succession of a 'positive' phase of hypercoagulability and a 'negative' phase of hypocoagulability was described by Wooldridge in a series of papers beginning in 1886.

To examine the process further it will be necessary to outline current concepts of blood coagulation and fibrinolysis before describing the changes observed, discussing their mechanism, and their possible significance.

\section{Blood Coagulation}

In 1964 it was proposed that the conversion of the soluble protein fibrinogen to insoluble fibrin was the culmination of a cascade (Macfarlane, 1964) or waterfall (Davie and Ratnoff, 1964) of proenzyme to enzyme transformations (Fig. 1).
The reactions proceed in a stepwise manner. Eact enzyme, distinguished for description from ite inactive precursor by the suffix $a$, has for its sub strate the next proenzyme in the sequence. The original proposals have been modified as addis tional information has become available based on studies with individual factors purified b\& chemical and immunological methods and n⿳̆ doubt more changes are to come (Davie, Hougie and Lundblad, 1969).

Pathways of stimulation which are intrinsio and extrinsic to the blood have been recognized Contact of blood with a foreign surface initiates the intrinsic pathway by conversion of Hagema factor (XII) to an enzyme (XIIa). In turn factor $X I$ and IX are activated. Activated Christmas factor (IXa) can convert factor $\mathrm{X}$ to $\mathrm{Xa}$ and this reaction proceeds faster when IXa forms a dis sociable complex with antihaemophilic globulin (VIII), phospholipid, and calcium (Hougieg

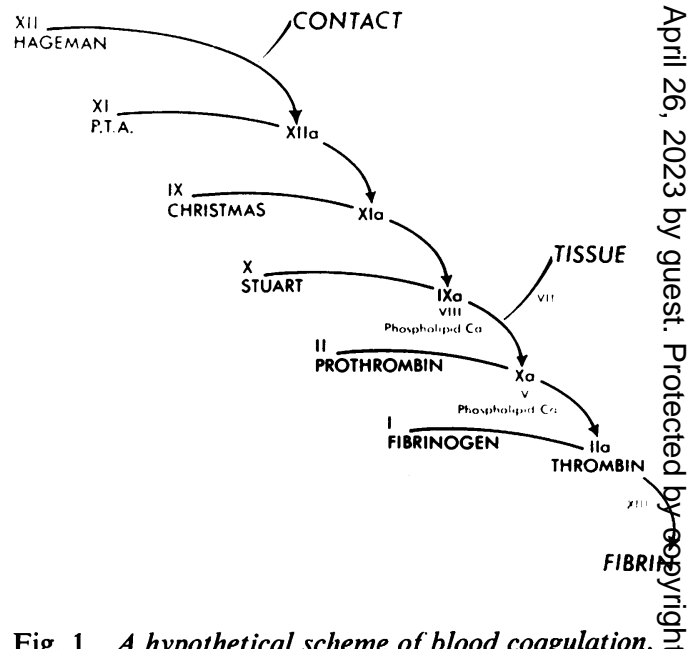

Fig. 1 A hypothetical scheme of blood coagulation. 
Denson, and Biggs, 1967). Foreign surfaces are known to include silica compounds, ellagic acid, sodium stearate, uric acid, human skin, and collagen but the precise circumstances under which such activation occurs in vivo are unknown. The particular physical properties which give coagulant activity to a surface are also undefined, although the importance of water wettability and surface negative charge have been postulated (Nossel, Rubin, Drillings, and Hsieh, 1968).

The extrinsic pathway, independent of factors VIII, IX, XI, and XII, is stimulated when coagulants from tissue microsomes enter the blood to form a complex with factor VII and calcium, also for the activation of factor $X$.

A complex of $\mathrm{Xa}, \mathrm{V}$, phospholipid, and calcium converts prothrombin to thrombin, an enzyme which splits specific fibrinopeptides from fibrinogen to convert it to fibrin (Laki and Gladner, 1964). Thrombin has other important roles in haemostasis. Trace amounts activate fibrinstabilizing factor (XIII) (Laki and Gladner, 1964), provoke the platelet aggregation, and release reactions which provide phospholipid catalysts for coagulation and other biologically active materials (Hellem and Stormorken, 1969), and convert factor VIII (Rapaport, Schiffman, Patch, and Ames, 1963) and factor V (Ware and Seegers, 1948) to more reactive forms. Thus factor VIII previously exposed to thrombin will increase the rate of action of IXa on factor X some 20 times. Large amounts of thrombin destroy factor VIII and factor $\mathrm{V}$ which are usually almost completely removed during coagulation of human blood in the test tube.

The relative importance of the intrinsic and extrinsic systems is an area of considerable doubt. Defects of either system alone may result in an increased tendency to haemorrhage while neither clearly protects against thrombosis. The patient in whom factor XII was discovered, John Hageman, recently died of pulmonary embolism after a fracture. It is difficult to envisage circumstances where damage to tissues could stimulate one pathway without affecting the other, and the distinction loses some of its importance now that similar intrinsic and extrinsic stimuli have been recognized for fibrinolysis.

\section{Blood Fibrinolysis}

Fibrinolytic activity depends on plasmin, a protease of broad specificity, which can be generated from plasminogen, a globulin with a distribution in the body similar to that of fibrinogen. A variety of activators (Fig. 2) achieve the conversion by opening a specific argininylvalyl bond in the plasminogen molecule (Summaria, Hsieh, and Robbins, 1967).

Insoluble activators of plasminogen are found in most body tissues (Albrechtsen, 1957) associated with the lysosomes (Lack and Ali, 1964), and their entry into the blood in states of tissue damage provides an analogy for the extrinsic pathway of blood coagulation. A soluble activator of plasminogen may be derived directly from vascular endothelial cells (Warren, 1964) or generated in the blood. Activator is formed when human plasma at acid $p \mathbf{H}$ and reduced ionic strength is incubated with kaolin, an effect which is strikingly reduced in the absence of Hageman factor (Niewiarowski and Prou-Wartelle, 1959; Iatridis and Ferguson, 1961). It has also been shown that some Hageman factor-deficient subjects fail to respond to physical exertion or venous occlusion by the normal increase in circulating activator (Iatridis, Iatridis, and Ferguson, 1966). However, Hageman factor does not appear to act directly but to catalyse the formation of a plasminogen activator from a precursor, distinguishable from the other known substrates of Hageman factor (Ogston, Ogston, Ratnoff, and Forbes, 1969). This is analogous to the intrinsic mechanism of blood coagulation.

In purified solution plasmin digests many of the coagulation factors, including fibrinogen, activates certain components of complement, inactivates peptide hormones, hydrolyses immunoglobulins, and digests even collagen. In plasma, however, a great excess of antiplasmins normally prevents the expression of all proteolytic activities other than the digestion of fibrin. It has been suggested that this specificity for fibrin is conferred by the site of action of the activator. Plasmin formed in the presence of fibrin appears to be protected from antiplasmins which would otherwise be completely inhibitory (Sherry, 1968). Alternatively, circulating plasmin-antiplasmin complexes may dissociate in the presence of fibrin (Ambrus and Markus, 1960). In both hypotheses, which are not mutually exclusive, the presence of

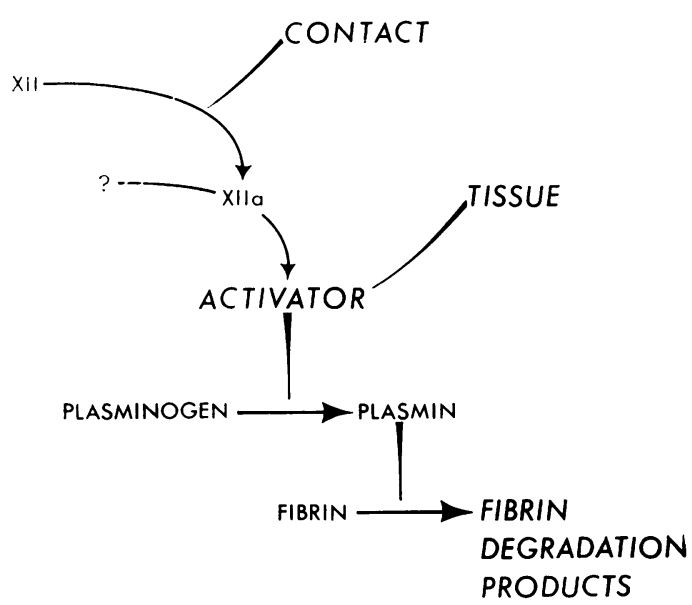

Fig. 2 A hypothetical scheme of blood fibrinolysis. 
fibrin determines any proteolytic action of plasmin at all in the very inhibitory environment of plasma.

\section{Blood Coagulation after Injury}

Although the natural stimulus for coagulation and for fibrinolysis is not known with any precision it is clear that both systems respond to similar intrinsic and extrinsic stimuli in vitro and the same is likely to be true in vivo. There are many examples of human disease where tissue damage can be shown to stimulate both systems. After injury direct tissue damage, damage to the cellular elements of the blood, shock and haemorrhage, hypoxia, infection, and fat embolism provide ample reason to expect exposure of the blood to foreign surfaces and the entry of tissue materials into the circulation.

The resulting changes have been well described in experimental animals (Bergentz and Nilsson, 1961; Penick, Roberts, and Dejanov, 1965; Hardaway, 1967; Leandoer, 1968), in injured patients (Innes and Sevitt, 1964; Hardaway, 1966, 1967, and 1968), and after surgery (Phillips, Malm, and Deterling, 1963; Sharp and Eggleton, 1963; Barkhan, 1969).

For purposes of description the reactions may be grouped into three phases: (1) circulation of active coagulation intermediates; (2) increased consumption of coagulation factors and platelets, leading to their decreased concentration in the blood; (3) increased synthesis of coagulation factors and release of platelets, leading to their increased concentration in the blood. It should be emphasized that this is a purely artificial separation; the phases will overlap, increased consumption may not be detected after minor injuries, and little is known of their relative duration. The intensity of the changes will be directly related to the degree of injury.

\section{Circulation of Active Intermediates}

Immediately after injury the clotting time is shortened and the clotting time of blood in siliconed tubes approaches that found in uncoated glass tubes. This apparent loss of the surface-activating effect of glass suggests that the contact factors are circulating in an activated form. At the same time there may be an increase in factor VIII levels as measured by one-stage assay, for which a possible reason would be the release of thrombin already described (Penick et al, 1965). However, a similar increase of factor VIII follows the injection of adrenaline (Ingram, 1961) and the precise mechanism is unknown.

The importance of this stage is shown by the experiments of Wessler and his associates
(Wessler and Yin, 1968a). The intravenous i fusion of normal human serum, but not of plasmg protected from surface contact, induces in rabbi跨 a transient hypercoagulable state during which massive thrombosis develops in large vascul $\overrightarrow{F^{5}}$ segments containing stagnant blood. The pheno: menon is still observed when the static blood s. $^{\circ}$ far removed from the site of infusion and the production of thrombi has been shown to depen on the presence in an area of stasis of activateg factors, namely, XIIa, XIa, and IXa. Thrombosís is not produced by stasis alone, or by activated factors alone, but by the combination of the two In addition suggestive evidence has been obtaines in animals that increases in factor VIII may pres? dispose to, though not initiate, thrombosis (Penick, Dejanov, Reddick, and Roberts, 1966\%?

It is important that the factors are present in the activated form. Factor Xa equivalent to the activity that can be derived from $10 \mathrm{ml}$ of plasma was thrombogenic in rabbits while the injection of non-activated factor $X$ equivalent to that which could be derived from 1 litre of plasma was not (Wessler and Yin, 1968b). The hypercoagu ability produced by the activated form persist for only 10 seconds after injection unless factor $\mathrm{Xa}$ was combined with a suitable phospholipie which prolonged its duration of action to 200 seconds. The rapid disappearance of factor may represent the action of plasma inhibitors of its clearance, like that of other activated coagula tion factors, into the reticuloendothelial cells of the liver (Spaet, 1962; Wessler, Yin, Gaston, an Nicol, 1967; Deykin, Cochios, DeCamp, an $\overrightarrow{6}$ Lopez, 1968). Only the activated clotting factors are rapidly cleared by the liver which appears discriminate between them and their non-activated forms. Though there is evidence that the clearance of factors XIIa and XIa may be slower than thatt of factor $\mathrm{Xa}$, this dangerous phase, when thron: bosis is likely in areas of stasis, probably ends rapidly once the stimulus to coagulation $\$$ removed.

\section{Increased Consumption of Coagulation Factors $\widetilde{N}$}

While active intermediates continue to circulares the obvious stimulation of coagulation may be replaced within a few hours, or even earlier 备 severe injuries, by a phase of apparent hypष् coagulability due to a loss of blood coagulation factors, which in fact represents even more intense stimulation.

Clotting time, prothrombin time, and parti周1 thromboplastin time are prolonged by the multiple deficiencies, which also coincide with fall in the blood platelet count. Any factor may be decreased; reductions of factor VIII and $\&$ are most frequently observed. Fibrinogen is on greatly reduced in the most severe examples.

The losses could be accounted for in part by 
bleeding or by leakage of intravascular contents into the tissues. They would be accentuated by dilution of the remaining plasma with extravascular fluid poor in protein as transcapillary refilling occurs and by the various fluids given by transfusion. The changes occur too rapidly for impaired synthesis to be responsible. These processes have been studied in man following burn injuries (Davies, Ricketts, and Bull, 1966) and in dogs subjected to severe haemorrhage (Leandoer, 1968) using preparations of fibrinogen labelled with radioactive iodine, and it has been clearly shown that often the preceding explanations do not suffice. With even moderately severe injuries the widespread activation of the coagulation and fibrinolytic systems uses up the factors more rapidly than they can be replaced.

The importance of intravascular coagulation is shown by the fall of the platelets, which would not be affected by fibrinolysis alone, and by the frequency with which cryoprofibrin can be demonstrated. Plasma collected at this time, particularly heparinized plasma, forms a precipitate when cooled to $4^{\circ} \mathrm{C}$ (cryoprofibrin), exposed to acid $p \mathrm{H}$, or treated with protamine or similar basic materials (Shainoff and Page, 1962; Kowalski, 1968; Lipinski and Worowski, 1968). The precipitate contains fibrin, the phenomenon has been called paracoagulation, and is thought to represent the precipitation of fibrin monomer previously held in a soluble complex with fibrinogen. Similar complexes, also soluble but incoagulable with thrombin and therefore found in the serum, are formed between fibrin monomer and the degradation products of fibrinolysis.

Further evidence of the importance of intravascular coagulation comes from the frequency with which widespread thrombosis of the microcirculation of different organs may be demonstrated at this stage. It will be necessary to return to the question of the relative importance of coagulation and fibrinolysis when the changes in the latter have been discussed.

\section{Increased Production}

A compensatory increase in output is the usual biological response of the intact organism to a decrease in the blood concentration of a particular constituent, however caused. This increase in output is also frequently excessive, as it appears to be in the case of platelets and coagulation factors whose production is increased following the phase of increased consumption, sometimes leading to blood levels of $800 \%$ or more. The increase in fibrinogen synthesis occurs very rapidly and can be demonstrated by radioactive fibrinogen studies within two hours of a major haemorrhage (Leandoer, 1968). An increased plasma fibrinogen level is usually already evident on the day after injury or surgical operation, rising progressively to a peak between seven and 10 days, and often persisting for several weeks. Increase of the platelet count is often relatively delayed so that thrombocytopenia may persist for several days before it is succeeded by a thrombocytosis. Increases of many of the blood coagulation factors, including factor VIII, may still be evident 10 to 20 days after fracture of a long bone (Davidson and Tomlin, 1963).

Although it might be reasonably argued that such an increase of clotting factors could predispose to thrombosis no such evidence of a causal effect has been presented. The experiments of Wessler, already quoted, show that the capacity to produce thrombi resides in the presence of the factors in the activated form. Presumably the circulation of active intermediates would continue during the phase of increased consumption, limited only by the availability of their precursors, but it remains uncertain whether this stimulus continues into the phase of increased production, or if so for how long. Certainly the effects of overproduction, taking into account the normal survival of the various constituents, could persist for some time after active intermediates are no longer being produced. It is, therefore, of considerable importance to determine whether the increased levels of factor VIII found at this stage are apparent, representing continuing activation by thrombin, or real due to increased synthesis of non-activated factor VIII. Some preliminary evidence (Penick et al, 1965 and 1966) suggests that the total quantity of factor VIII is increased.

\section{Blood Fibrinolysis after Injury}

As with coagulation the immediate effect is an apparent stimulation of fibrinolysis, with increased circulating activator of plasminogen giving a decrease in blood clot and euglobulin clot lysis times. A similar increase is found after exercise, emotion, or the injection of adrenaline (Iatridis and Ferguson, 1963; Cash and Allan, 1967a and b). This is followed by a phase of apparent reduction in circulating activator with prolonged lysis times, a finding which may persist for several weeks (Franz, Kark, and Hathorn, 1961; Davidson and Tomlin, 1963; Innes and Sevitt, 1964; Borowiecki and Sharp, 1969). However, this coincides with a rapid fall in blood plasminogen which suggests increased consumption of this protein and an increase in fibrin degradation products in the serum. Together these show that fibrinolysis remains very active. Fibrin degradation products retain the antigenic properties of fibrinogen and can be recognized in the serum as material, incoagulable with thrombin, which inhibits the reaction of an antifibrinogen serum in a variety of sensitive assay systems (Merskey, Kleino, and Johnson, 1966; Allington, 1967; Merskey, Lalezari, and Johnson, 1969). 
Proof of the activity of fibrinolysis under these circumstances is provided by studies with radioactive fibrinogen in dogs following experimental haemorrhage (Leandoer, 1968) and similar experiments with the infusion of coagulants, either thrombin (Nordström, Blomback, Olsson, and Zetterquist, 1967), tissue thromboplastins (Nordström and Zetterqvist, 1969), or active material derived from postpartum human serum (Zetterqvist, 1969), which reproduce the blood changes of injury. The initial fall in circulating radioactivity, accompanied by the formation of capillary microthrombi, is followed shortly afterwards by a reappearance of circulating radioactivity, which is protein bound but incoagulable with thrombin. This has been shown to represent the presence of fibrin degradation products bearing the radioactive label. This rebound of radioactivity can be blocked with fibrinolytic inhibitors and is accompanied by a fall in circulating plasminogen. Circulating plasminogen activator may be slightly increased but is often normal, or even reduced, perhaps because of adsorption to the fibrin deposits.

There is no need to assume that in vivo fibrinolysis is necessarily a simple function of the amount of plasminogen activator detectable in cubital vein blood. Indeed, there is good evidence to the contrary. Activator is cleared rapidly from the blood by lungs and liver (Menon, Weightman, and Dewar, 1969). Experiments with animals (Tsapogas and Flute, 1964) and clinical experience with infusions of streptokinase and urokinase show that a very high level of activator can be present in a local area of the circulation and yet give little direct evidence of its presence in venous blood taken from a remote site. A high concentration of natural activator in uterine venous blood with little change in cubital vein blood has also been demonstrated during Caesarian section (Basu, 1969; Prentice, McNicol, and Douglas, 1969). Local activity can be recognized indirectly only if it is sufficiently intense and prolonged to produce a reduction in circulating plasminogen and an increase in fibrin degradation products Flute, 1964 and 1965). The validity of single measurements of activator as an indicator of overall thrombolysis has also been questioned by Cash (1968) who has investigated differences between individuals in their capacity to respond to recognized stimuli.

A similar phenomenon suggestive of local fibrinolysis, with reduced activator, reduced plasminogen, and increased fibrin degradation products, is produced by the intravenous administration of Arvin, a purified fraction of the venom of the Malayan pit viper (Regoeczi, Gergely, and McFarlane, 1966; Kakkar, Flanc, Howe, O'Shea, and Flute, 1969; Pitney, Bell, and Bolton, 1969). This digests fibrinogen to form microclots but does so independently of the coagulation enzymes. It may be that the appearance of fibrin is the trigger for plasminogen depletion, increase in fibrin degradation product and local activator release.

\section{Coagulation versus Fibrinolysis}

The phase of increased consumption is sometime associated with abnormal bleeding, particularl from areas of tissue damage where the characis teristic appearance is the paradoxical association of haemorrhage and thrombosis. This kind $\vec{\phi} \vec{\Phi}$ bleeding is uncommon and is found primarily i $\overrightarrow{\mathrm{n}}$ those with massive injury or severe haemorrhages from other causes. In such cases, both coagulation and fibrinolysis are increased and the question arises as to which is mainly responsible for the bleeding. The question is far from academic as it is often necessary to decide in a particular case of sudden haemostatic failure whether to rely on transfusion of blood and blood products alone to give anticoagulants, or to inhibit fibrinolysis

Platelet and coagulation factor concentration in the blood could be reduced below the criticat levels for haemostasis if they are used up in the process of coagulation. Similar reductions in coagulation factors, though not of platelets? could be produced by fibrinolysis sufficient to cause the uncontrolled action of plasmin. The increase in fibrin degradation products ma contribute to the haemorrhagic state, for theso products of fibrinolysis, when not complexeक with fibrin monomer, inhibit the action of throme bin and other coagulation enzymes, cause defec $\vec{\nabla}$ tive polymerization of fibrin monomer, and block platelet adhesion, aggregation, and release reactions (Kowalski, 1968).

Final judgment of the relative importance of the two systems must await more definite ident? fication of specific intermediates in individua cases, not possible at present. Perhaps the fibriin formation of coagulation could be measure from the amount of circulating fibrinopeptides the specific fragments released from fibrinogen by thrombin. Fibrinolysis, which is desirable and fibrinogenolysis, which may indicate the uncontrolled action of plasmin, could be separateक if it were possible to distinguish between theo degradation products of the two reactions However, there is good evidence from experit mental and clinical studies that reversal of coagulation is the more important and thef inhibition of fibrinolysis alone may be dangerous? In experimental studies with labelled fibrinogen the decrease of platelets, fibrinogen, and plasminoge $\overline{\underline{Q}}$ and all the changes in plasma radioactivity, tha is to say, both coagulation and fibrinolysis reactions, are blocked by the administration of heparin before bleeding or the infusion of coagulants (Zetterqvist, 1969). It should be enf phasized that heparin, in the doses given, woule. have no direct inhibitory effect on fibrinolysis? this is a biological effect in the intact organism, 
preventing the formation of fibrin appears to prevent fibrinolysis. In the experimental studies heparin has usually been given before the stimulus to coagulation but there is good evidence that heparin will also correct the changes in fibrinolysis in human patients already suffering from the effects of disseminated intravascular coagulation (Merskey, Johnson, Pert, and Wohl, 1964; Straub, Riedler, and Frick, 1967; Robboy, 1969). An example observed by the author is illustrated in Figure 3. In these and other patients heparin has been given with success even while the patient is actually bleeding (von Francken, Johansson, Olsson, and Zettergvist, 1963; Verstraete, Amery, Vermylen, and Robyn, 1963; Merskey, 1968).

The administration of specific fibrinolytic inhibitors, epsilon-aminocaproic acid, tranexamic acid, or Trasylol, blocks only the fall of plasminogen and secondary release of fibrin degradation products in the experimental situation while allowing the fall in platelets, fibrinogen, and coagulation factors, and therefore the tendency to microthrombosis, to proceed unchecked. The inhibition of fibrinolysis increases fibrin deposition in the organs which could contribute to further tissue damage (Ratnoff, 1969). It has been shown (Wessler, Freiman, Suyemoto, and Reimer, 1961) that it is not possible to produce thrombi in areas of stasis within the small vessels of the hamster cheek pouch by injections of serum, which are sufficient to cause massive thrombosis in an isolated segment of the jugular vein of the same animal, unless the animals are pretreated with fibrinolytic inhibitors. Fibrinolysis therefore seems to be more active in the microcirculation. Whether this implies a qualitative difference in fibrinolytic potential in vessels of differing size or merely reflects a greater

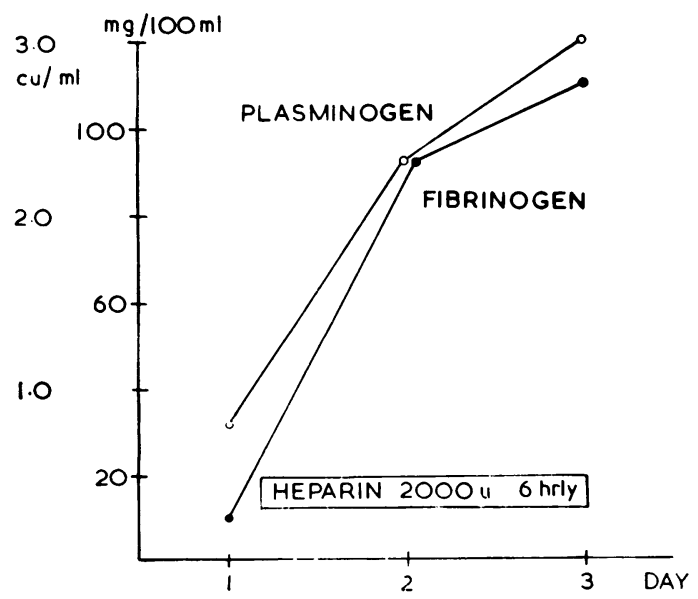

Fig. 3 Effect of heparin treatment on plasma plasminogen and fibrinogen in a patient with disseminated intravascular coagulation and secondary fibrinolysis. surface-to-volume ratio in the small vessels is unknown.

\section{Significance of the Changes}

Injury, therefore, stimulates blood coagulation and fibrinolysis concurrently. This would be the expected and desirable response, providing a mobilization of resources for haemostasis and tissue repair. The stimulation would be held in check and localized, so far as possible, to areas of damage by a variety of highly efficient compensation mechanisms equally significant to the coagulation and fibrinolytic systems (Fig. 4). Circulating enzyme inhibitors are supplemented by the rapid and selective clearance of the activated factors into cells of the reticuloendothelial system of the liver and elsewhere. This requires the continuation of blood flow which, as seen already in this symposium, may itself be affected by injury. Arterial hypotension, arteriolar constriction, the opening of fresh capillaries, and arteriovenous shunts contribute to reductions in tissue perfusion (Hardaway, James, Anderson, Bredenberg, and West, 1967; Hardaway, 1968). Changes in the rheological properties of the blood itself must also be mentioned, particularly the increase of fibrinogen and haemoconcentration (Replogle, 1969). In addition, flow may be affected by platelet adhesion and aggregation, which will also have modifying effects on coagulation and fibrinolysis (Hellem and Stormorken, 1969).

Fibrinolysis is the only recognized compensation for fibrin in static blood. It serves the dual function of dissolving fibrin deposits and providing a supply of fibrin degradation products which will hold additional fibrin monomer in

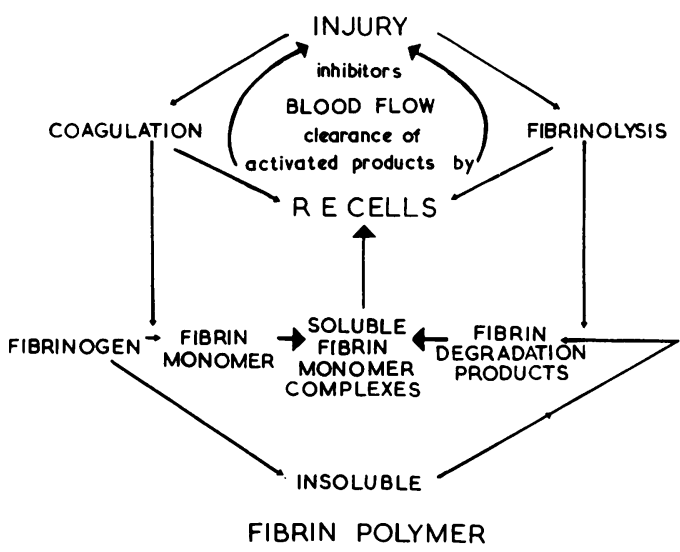

Fig. 4 Compensating processes following stimulation of coagulation and fibrinolysis. 
solution, and thereby allow its carriage to fixed cells of the reticuloendothelial system for final disposal.

When these compensating mechanisms fail 'disseminated' intravascular coagulation may cause widespread thrombosis of the microcirculation with the possibility of the shock, bleeding, and tissue necrosis of the defibrination syndrome. For longer periods the presence of circulating active intermediates of coagulation implies a risk of 'localized' intravascular coagulation, thrombosis of major vessels in areas of stasis. Perhaps this tendency continues, in some measure, until all the injuries are finally healed and the stimulation of cellular damage to coagulation and fibrinolysis is at an end.

\section{References}

Albrechtsen, O. K. (1957). The fibrinolytic activity of human tissues. Brit. J. Haemat., 3, 284-291.

Allington, M. J. (1967). Fibrinogen and fibrin degradation products and the clumping of staphylococci by serum. Brit. $J$. Haemat., 13, 550-567.

Ambrus, C. M., and Markus, G. (1960). Plasmin-antiplasmin complex as a reservoir of fibrinolytic enzyme. Amer. $J$. Physiol., 199, $491-494$.

Rarkhan, P. (1969). Haematological consequences of major surgery. Brit. J. Haemat., 17, 221-224.

Basu, H. K. (1969). Fibrinolysis and abruptio placentae. J. Obstet. Gynaec. Brit. Cwlth, 76, 481.

Bergentz, S. E., and Nilsson, I. M. (1961). Effect of trauma on coagulation and fibrinolysis in dogs. Acta chir. scand., 122, 21-29.

Borowiecki, B., and Sharp, A. A. (1969). Trauma and fibrinolysis. J. Trauma, 9, 522-536.

Cash, J. D. (1968). A new approach to studies of the fibrinolytic enzyme system in man. Amer. Heart J., 75, 424-428.

Cash, J. D., and Allan, A. G. E. (1967a). The effect of mental stress on the fibrinolytic reactivity to exercise. Brit. med. J., 2, 545-548.

Cash, J. D., and Allan, A. G. E. (1967b). The fibrinolytic response to moderate exercise and intravenous adrenaline in the same subjects. Brit. J. Haemat., 13, 376-383.

Davidson, E., and Tomlin, S. (1963). The levels of the plasma coagulation factors after trauma and childbirth. J. clin. Path., 16, 112-114.

Davie, E. W., and Ratnoff, O. D. (1964). Waterfall sequence for intrinsic blood clotting. Science, 145, 1310-1312.

Davie, E. W., Hougie, C., and Lundblad, R. L.(1969). Mechanisms of blood coagulation. In Recent Advances in Blood Coagulation, edited by L. Poller, pp. 13-28. Churchill, London.

Davies, J. W. L., Ricketts, C. R., and Bull, J. P. (1966). Studies of plasma protein metabolism. III. Fibrinogen in burned patients. Clin. Sci., 30, 305-314.

Deykin, D., Cochios, F., DeCamp, G., and Lopez, A. (1968). Hepatic removal of activated factor $X$ by the perfused rabbit liver. Amer. J. Physiol., 214, 414-419.

Flute, P. T. (1964). The assessment of fibrinolytic activity in the blood. Brit. med. Bull., 20, 195-199.

Flute, P. T. (1965). Fibrinolysis in relation to thrombosis. Ann. roy. Coll. Surg. Engl., 36, 225-234.

Francken, I. von., Johansson, L., Olsson, P., and Zetterqvist, E. (1963). Heparin treatment of bleeding. Clinical observations. Lancet, $1,70-73$.

Franz, R. C., Kark, A. E., and Hathorn, M. (1961). Post operative thrombosis and plasma fibrinolytic activity. A comparative study in Africans, Indians and Whites. Lancet, 1, 195-197.

Hardaway, R. M., III (1966). Syndromes of Disseminated Intravascular Coagulation. Thomas, Springfield, Ill.

Hardaway, R. M., III (1967). Disseminated intravascular coagulation in experimental and clinical shock. Amer. J. Cardiol., 20,161-173.

Hardaway, R. M., III (1968). Clinical Management of Shock. Thomas, Springfield, IIl.

Hardaway, R. M., III, James, P. M., Jr., Anderson, R. W., Bredenberg, C. E., and West, R. L. (1967). Intensive study and treatment of shock in man. J. Amer. med. Ass., 199, 779-790.

Hellem, A. J., and Stormorken, H. (1969). Platelet adhesion- aggregation reaction and its clinical significance. In Recert. Advances in Blood Coagulation, edited by L. Poller, pp 69-106. Churchill, London.

Hewson, W. (1772, repr. 1846). An enquiry into the propertie् of the blood. Experiment XXI. In The Works of Willia) Hewson, F.R.S., edited by G. Gulliver, pp. 46-50. Syder? ham Society, London.

Hougie, C., Denson, K. W. E., and Biggs, R. (1967). A study the reaction products of factor VIII and factor IX by ge I+ filtration. Thrombos. Diathes. haemorrh. (Stuttg.), 18 211-222.

Hunter, J. (1794). A Treatise on the Blood, Inflammation, an Gunshot Wounds, p. 26. G. Nicoll, London.

Iatridis, S. G., and Ferguson, J. H. (1961). Effect of surfac ang Hageman factor on the endogenous or spontaneoys activation of the fibrinolytic system. Thrombos. Diathe haemorrh. (Stuttg.), 6, 411-423.

Iatridis, S. G., and Ferguson, J. H. (1963). Effect of physica $\vec{P}$ exercise on blood clotting and fibrinolysis. J. appl. Physiol 18, 337-344.

Iatridis, S. G., Iatridis, P. G., and Ferguson, J. H. (1966). The row of HF (Factor XII) in the pathogenesis of the thromboly tiह state induced by venous occlusion. Thrombos. Diathe haemorrh. (Stuttg.), 16, 207-217.

Ingram, G. I. C. (1961). Increase in antihaemophilic globulif̧ activity following infusion of adrenaline. J. Physiol. (Lond. $\AA$ 156, 217-224.

Innes, D., and Sevitt, S. (1964). Coagulation and fibrinolys is ift injured patients. J. clin. Path., 17, 1-13.

Kakkar, V. V., Flanc, C., Howe, C. T., O'Shea, M., and Flute, P. T. (1969). Treatment of deep vein thrombosis. A trial of heparin, streptokinase, and Arvin. Brit. med. J., 1, 806-810.

Kowalski, E. (1968). Fibrinogen derivatives and their biologic activities. Semin. Haemat., 5, 45-59.

Lack, C. H., and Ali, S. Y. (1964). Tissue activator of plasming gen. Nature (Lond.), 201, 1030-1031.

Laki, K., and Gladner, J. A. (1964). Chemistry and physiology the fibrinogen-fibrin transition. Physiol. Rev., 44, 127-160.

Leandoer, L. (1968). Fibrinogen after massive haemorrhage Studies on coagulation and fibrinolysis of blood and lympS in dogs. Acta chir. scand., Suppl., 390.

Lipinski, B., and Worowski, K. (1968). Detection of soluble fibrib monomer complexes in blood by means of protamine sulphate test. Thrombos. Diathes. haemorrh. (Stuttg.), 20: 44-49.

Macfarlane, R. G. (1964). An enzyme cascade in the blood clotting mechanism, and its functions as a biochemic\& amplifier. Nature (Lond.), 202, 498-499.

Menon, I. S., Weightman, D., and Dewar, H. A. (1969). The rolen of the lung in blood fibrinolysis. Clin. Sci., 36, 427-433.

Merskey, C., Johnson, A. J., Pert, J. H., and Wohl, H. (1964Bె Pathogenesis of fibrinolysis in defibrination syndromes effect of heparin administration. Blood, 24, 701-715.

Merskey, C., Kleiner, G. J., and Johnson, A. J. (1966). Quant? tative estimation of split products of fibrinogen in human: serum, relation to diagnosis and treatment. Blood, 28, 1-1\&

Merskey, C. (1968). Diagnosis and treatment of intravascular coagulation. Brit. J. Haemat., 15, 523-526.

Merskey, C., Lalezari, P., and Johnson, A. J. (1969). A rapif?. simple, sensitive method for measuring fibrinolytic spl: products in human serum. Proc. Soc. exp. Biol. (N.Y. 1?1, 871-875.

Morgagni, G. B. (1769). The Seats and Causes of Diseases, vol. 옥 p. 186. A. Millar, London.

Niewiarowski, S., and Prou-Wartelle, O. (1959). Rôle du facteu contact (facteur Hageman) dans le fibrinolyse. Thrombos. Diathes. haemorrh. (Stuttg.), 3, 593-603.

Nordström, S., Blomback, M., Olsson, P., and Zetterquist, E (1967). Experimental investigations with proteinase inhibitors. Acta chir. scand., Suppl., 378, 33-40.

Nordström, S., and Zetterqvist, E. (1969). Effects of EACA anß Trasylol on thromboplastin-induced intravascular cow agulation, studied in dogs with iodine-labelled fibrinogerס Acta physiol. scand., 76, 93-105.

Nossel, H. L., Rubin, H., Drillings, M., and Hsieh, R. (1968 Inhibition of Hageman factor activation. J. clin. Invest 47, 1172-1180.

Ogston, D., Ogston, C. M., Ratnoff, O. D., and Forbes, C. D. (1969). Studies on a complex mechanism for the activation of plasminogen by kaolin and by chloroform: the part 0 cipation of Hageman factor and additional co-factor $\vec{D}$ J. clin. Invest., 48, 1786-1801.

Penick, G. D., Roberts, H. R., and Dejanov, I. I. (1965). Cove $\vec{P}$ intravascular clotting. Fed. Proc., 24, 835-839.

Penick, G. D., Dejanov, I. I., Reddick, R. L., and Roberts, H. 返 (1966). Predisposition to intravascular coagulatiop Thrombos. Diathes. haemorrh. (Stuttg.), Suppl. 21, 543-550

Phillips, L. L., Malm, J. R., and Deterling, R. A., Jr. (1963 Coagulation defects following extracorporeal circulation. Ann. Surg., 157, 317-326. 


\section{Coagulation and fibrinolysis after injury}

Pitney, W. R., Bell, W. R., and Bolton, G. (1969). Blood fibrinolytic activity during Arvin therapy. Brit. J. Haemat., 16, 165-171.

Prentice, C. R. M., McNicol, G. P., and Douglas, A. S. (1969). Plasminogen activation and the coagulation process. $J$. clin. Path., 22, 367-.368.

Rapaport, S. I., Schiffman, S., Patch, M. J., and Ames, S. B. (1963). The importance of activation of antihaemophilic globulin and proaccelerin by traces of thrombin in the generation of intrinsic prothrombinase activity. Blood, 21, 221-236.

Ratnoff, O. D. (1969). EACA-a dangerous weapon. New Engl. J. Med., 280, 1124-1125.

Regoeczi, E., Gergely, J., and McFarlane, A. S. (1966). In vivo effects of Agkistrodon Rhodostoma venom: studies with fibrinogen-131. J. clin. Invest., 45, 1202-1212.

Replogle, R. L. (1969). The nature of blood sludging and its relationship to the pathophysiological mechanisms of trauma and shock. J. Trauma, 9, 675-683.

Robboy, S. (1969). Intravascular coagulation versus fibrinolysis. New Engl. J. Med., 281, 619.

Shainoff, J. R., and Page, I. H. (1962). Significance of cryoprofibrin in fibrinogen-fibrin conversion. J. exp. Med., 116, 687-707.

Sharp, A. A., and Eggleton, M. J. (1963). Haematology and the extracorporeal circulation. J. clin. Path., 16, 551-577.

Sherry, S. (1968). Fibrinolysis. Ann. Rev. Med., 19, 247-268.

Spaet, T. H. (1962). Studies on the in vivo behaviour of blood coagulation product I in rats. Thrombos. Diathes. haemorrh. (Stuttg.), 8, 276-285.

Straub, P. W., Riedler, G., and Frick, P. G. (1967). Hypofibrinogenaemia in metastatic carcinoma of prostate: suppression of systemic fibrinolysis by heparin. J. clin. Path., 20, 152-157.
Summaria, L., Hsieh, B., and Robbins, K. C. (1967). The specific mechanism of activation of human plasminogen to plasmin. J. biol. Chem., 242, 4279-4283.

Tsapogas, M. J., and Flute, P. T. (1964). Experimental thrombolysis with streptokinase and urokinase. Brit. med. Bull., 20, 223-227.

Verstraete, M., Amery, A., Vermylen, G., and Robyn, G. (1963). Heparin treatment of bleeding. Lancet, 1, 446.

Ware, A. G., and Seegers, W. H. (1948). Serum ac-globulin: formation from plasma ac-globulin; role in blood coagulation; partial purification; properties, and quantitative determination. Amer. J. Physiol., 152, 567-576.

Warren, B. A. (1964). Fibrinolytic activity of vascular endothelium. Brit. med. Bull., 20, 213-214.

Wessler, S., Freiman, D. G., Suyemoto, J., and Reimer, S. M. (1961). Serum thrombotic accelerator (STA) activity: a possible key to massive venous thromboembolism in man. Trans. Ass. Amer. Phycns, 74, 111-117.

Wessler, S., and Yin, E. T. (1968a). On the mechanism of thrombosis. Prog. Hemat., 6, 201-232.

Wessler, S., Yin, E. T., Gaston, L. W., and Nicol, I. (1967). A distinction between the role of precursor and activated forms of clotting factors in the genesis of stasis thrombi. Thrombos. Diathes. haemorrh. (Stuttg.), 18, 12-23.

Wessler, S., and Yin, E. T. (1968b). Experimental hypercoagulable state induced by Factor X: comparison of the nonactivated and activated forms. J. Lab. clin. Med., 72, 256-260.

Wooldridge, L. C. (1886). Über intravasculäre Gerinnungen. Arch. anat. Physiol. (Physiol. Abth.), 397-399.

Zetterqvist, E. (1969). Elimination of iodine labelled fbrinogen in intravascular coagulation and in the normal state. Experimental and clinical studies. Acta physiol. scand., Suppl., 325. 